\title{
Steady State Testing of an Organic Rankine Cycle Designed for Exhaust Heat Recovery Applications in Truck Engines
}

\author{
Thaddaeus Julius', Tanimu Kogi Ibrahim ${ }^{1}$, Ezeaku Ikeokwu Innocent ${ }^{2}$, Apostolos Pesyridis ${ }^{3}$, \\ Ahmed Mohammed ${ }^{3}$, Fuhaid Aziz Alshammari ${ }^{4}$ \\ ${ }^{1}$ Mechanical Engineering, Federal University Wukari, Wukari, Nigeria \\ ${ }^{2}$ Mechanical Engineering, Abia State University, Uturu, Nigeria \\ ${ }^{3}$ Mechanical Engineering, Brunel University London, Uxbridge, UK \\ ${ }^{4}$ Mechanical Engineering, University of Hail, Hail, Saudi Arabia
}

Email address:

thaddeus.julius@fuwukari.edu.ng (T. Julius)

\section{To cite this article:}

Thaddaeus Julius, Tanimu Kogi Ibrahim, Ezeaku Ikeokwu Innocent, Apostolos Pesyridis, Ahmed Mohammed, Fuhaid Aziz Alshammari. Steady State Testing of an Organic Rankine Cycle Designed for Exhaust Heat Recovery Applications in Truck Engines. International Journal of Sustainable and Green Energy. Vol. 10, No. 1, 2021, pp. 7-12. doi: 10.11648/j.ijrse.20211001.12

Received: December 28, 2020; Accepted: January 14, 2021; Published: January 22, 2021

\begin{abstract}
The transport sector is presently accountable for $1 / 4$ of total greenhouse gas released to the atmosphere, with road transportation depicting $17.8 \%$ of the total transport emissions contributing to global warming's growing threats caused by the continuous release of exhausting gases from internal combustion engines (ICEs). These exhaust threats call for improved sustainable ways of deploying fossil fuel in an environmentally friendly manner. Many sustainable solutions have been suggested recently with others already in the market; however, another promising sustainable solution is the Organic Rankine Cycle (ORC) application on-board automobiles, which is still developing stage with the prospect of entering the market soon. This paper presents the results from the thermal performance testing of an ORC system coupled to a commercial truck engine for exhaust heat recovery, which otherwise is exhausted to the environment causing pollution and other environmental threats. The test was performed to complement a study on the potential viability of installing an ORC based exhaust heat recovery (EHR) system on-board highway trucks for improving the truck's thermal performance without added fuel consumption. The testing carried out at $40 \%$ of rated load, and $1700 \mathrm{rpm}$ engine speed achieved $4.22 \mathrm{~kW}, 3.67 \mathrm{~kW}$, and $5.28 \%$ for peak power output, net power output, and cycle thermal efficiency of the ORC model, respectively. These results imply that installing the ORC system on-board long-haul trucks for exhaust heat recovery has a promising future.
\end{abstract}

Keywords: Steady State, Organic Rankine Cycle, Exhaust Heat Recovery, Commercial Truck Engines, Thermal Performance, Environmental Threats

\section{Introduction}

The application of Organic Rankine Cycle (ORC) based technology for exhaust heat recovery (EHR) for thermal efficiency improvement in Internal Combustion Engines (ICEs) has been heavily researched recently because of the inefficiency of the ICEs in converting the energy content of the fuel into useful work and the negative environmental effect emanating from the released of these exhausting gases from ICEs into the atmosphere. From the total heat supplied to the combustion engine in the form of fuel, approximately 30 to $40 \%$ is transformed into useful mechanical work, with the remaining heat released to the environment through exhaust gases and engine cooling systems, giving rise to entropy increase and severe environmental pollution, [1]. ORC system as a means of exhausting heat recovery has been implemented in some industrial procedures and on-board ship vessels with more than 100 plants operating to generate electricity commercially worldwide [2]. However, the application of this ORC technology on-board mobile vehicles is still a matter of academic studies and laboratory testing 
because of the adverse effects of added weight and space restrictions on the vehicles $[3,4]$.

Some experimental studies on applying ORC systems for exhaust heat recovery are reported in this study. In 2009, Wang et al. studied a compliance-based scroll compressor's empirical testing as an expander to evaluate the system's performance. The expander was investigated using R134a as the working fluid, and the power output was measured. The model achieved a maximum isentropic efficiency of $77 \%$ and a maximum output shaft output of approximately $1 \mathrm{~kW}$ [5]. Similarly, in 2012, Qui et al. carried out an experimental study of a biomass-fired ORC-based micro-CHP system designed for domestic applications. The strategy results in $861 \mathrm{~W}$ electricity and $47.26 \mathrm{~kW}$ heat, representing $1.41 \%$ electricity generation efficiency and $78.69 \%$ of CHP efficiency [6]. While in 2013, Zheng et al. carried out a verification study of a rolling-piston expander for application in low-temperature ORC systems. The research was done purposely to investigate the effectiveness of the proposed expander for application in ORC systems. The study results demonstrate that the expander runs from 350 to $800 \mathrm{rpm}$, achieving the output power of $350 \mathrm{~W}$ maximum with a heat temperature source of less than $90^{\circ} \mathrm{C}$. The model also achieved a cycle efficiency of 5\% [7].

Jung et al., in 2015, studied the feasibility of employing zeotropic mixture as working fluid in a lab-scale ORC system test bench experimentally. The performance of the zeotropic mix of R245fa and R365mfc (48.5\%/51.5\% molebased) was evaluated for steady-state activity in the ORC scroll expander method. The system used exhaust gas from a $30 \mathrm{~kW}$ Gas turbine as a heat source, and the study achieved $0.7 \mathrm{~kW}$ generated electricity and $3.9 \%$ ORC system efficiency [8]. In the same year, Galindo et al. carried out an ORC system's experimental study installed onto a $2 \mathrm{~L}$ turbocharged gasoline engine with ethanol as a working fluid. The study achieved a maximum ICE mechanical efficiency of $3.7 \%$ and $1.83 \mathrm{~kW}$ expander shaft power after 28 steady-state operating points were measured to examine the swash-plate expander model [9]. In 2016, an experimental testing of a singlecylinder, 4-strokes diesel engine was performed to calculate the available energy in the diesel engine's exhaust gas using water as a working fluid. A maximum recoverable energy of $17 \mathrm{~kW}$ achieved from the engine exhaust gas when running at $1400 \mathrm{rpm}$, while $39 \mathrm{~kW}$ was obtained at $2200 \mathrm{rpm}$ engine speed. The results also showed that $50 \%$ of the engine load is wasted, which could be recovered and converted to useful work [10]. In the same 2016, Kolasin' ski et al. reports on experimental and numerical studies of a rotary vane expander applied in a micro-scale ORC system. The results indicate that vane expanders are less expensive and mechanically simple than other expanders for ORC systems [11].

In 2017, Bianch et al. investigated a prototype micro-ORC energy recovery system's performance and main characteristics using R134a as a working fluid. Hot water with a temperature below $100^{\circ} \mathrm{C}$ is used as the heat source to study the low enthalpy heat recovery process in a LabView platform. The study achieved 0.30 to $1.2 \mathrm{~kW}$ electric power output with a gross efficiency range of $2.9-4.4 \%$ while the expander efficiency of $35-42 \%$, [12]. In the same 2017 , Li et al. carried out an experimental study of a small-scale ORC system designed for low-grade thermal energy recovery applications. The study achieved $5.405 \mathrm{~kW}$ at the specified $23^{\circ} \mathrm{C}$ cooling water temperature and 7.3 pressure ratio, respectively. The results revealed that the turboexpander output and the cycle efficiency increased with lower cooling water temperatures [13]. In 2018, Alshammari et al. studied a radial inflow turbine expander's performance with a novel back-swept blading applied for WHR in heavy-duty diesel engines. The investigation results in $4.3 \%$ efficiency, $6.3 \mathrm{~kW}$ maximum power generated, and a pressure ratio of 5.9 maximum [14, 15]. Finally, in 2019 Volkswagen and MAN prototyped integrating the WHR system into two conventional production vehicles: Golf 7, 2-1 TFSI EA888, and Demo truck D2676 LF25 Euro VI, respectively. The prototypes showed a $75 \%$ evaporator efficiency and a corresponding 3\% reduction in fuel consumption. The research group is now on the lookout to improve the WHR system's potential by employing an arrangement for the combined electrical/mechanical use of expander power [16].

It is evident from the consulted experimental studies that little information exists for prototyped models designed for exhaust heat to power in commercial truck engines for thermal efficiency improvement, which otherwise is exhausted to the environment. Consequently, this present study reports the testing of an ORC model designed for exhaust heat recovery in commercial truck engines with an objective function of evaluating an ORC model's performance coupled to the truck engine.

\section{Methodology}

To recover the thermal energy in the exhaust of commercial truck engines, an ORC model coupled to a 7.2L Yuchai engine was experimented with to examine the technology's waste heat recovery potential using thermal oil and R245fa fluids for this model because of its effective application in automobile ORC systems. The experimental research with the objective function of generating additional thermal energy with extra consumption. The model corresponds to a Yuchai diesel engine used in commercial trucks with engine specifications found on the manufacturer's website [17]. The exhaust gas's thermal energy is recovered and converted to electricity via an ORC-based system using $\mathrm{R} 245 \mathrm{fa}$ as a working fluid. The generated electricity is stored in a power bank installed in the system. The experimental test-bench set-up is shown in Figure 1, while Figure 2 and Figure 3 depict other significant components of this study's test bench.

The truck engine's exhaust gas thermal energy is used to heat thermal oil in the shell and tube heat exchanger and then exhaust to the ambient via the vent at the process $1^{\prime}-1^{\prime \prime}$, which then serves as the heat source to the evaporator used in vaporizing the working fluid. The ORC loop processes involved in converting the exhaust thermal energy into 
electricity start with preheating the working with the working fluid exiting the turbine before entering the condenser, process 1-2. The preheated working fluid then enters the evaporator, where it exchanges thermal energy with the thermal oil. It then vaporizes to high temperature, highpressure vapor, which then enters the expansion machine, process 2-3. High temperature vapour now expands in the turbine to produce mechanical power in the shaft, converted to electricity via the electric generator coupled to the turbine, process 3-4. The low pressure working at this point loses some thermal energy in the recuperator and then enters the condenser where it condenses back to liquid. The cycle starts again, process 4-1.

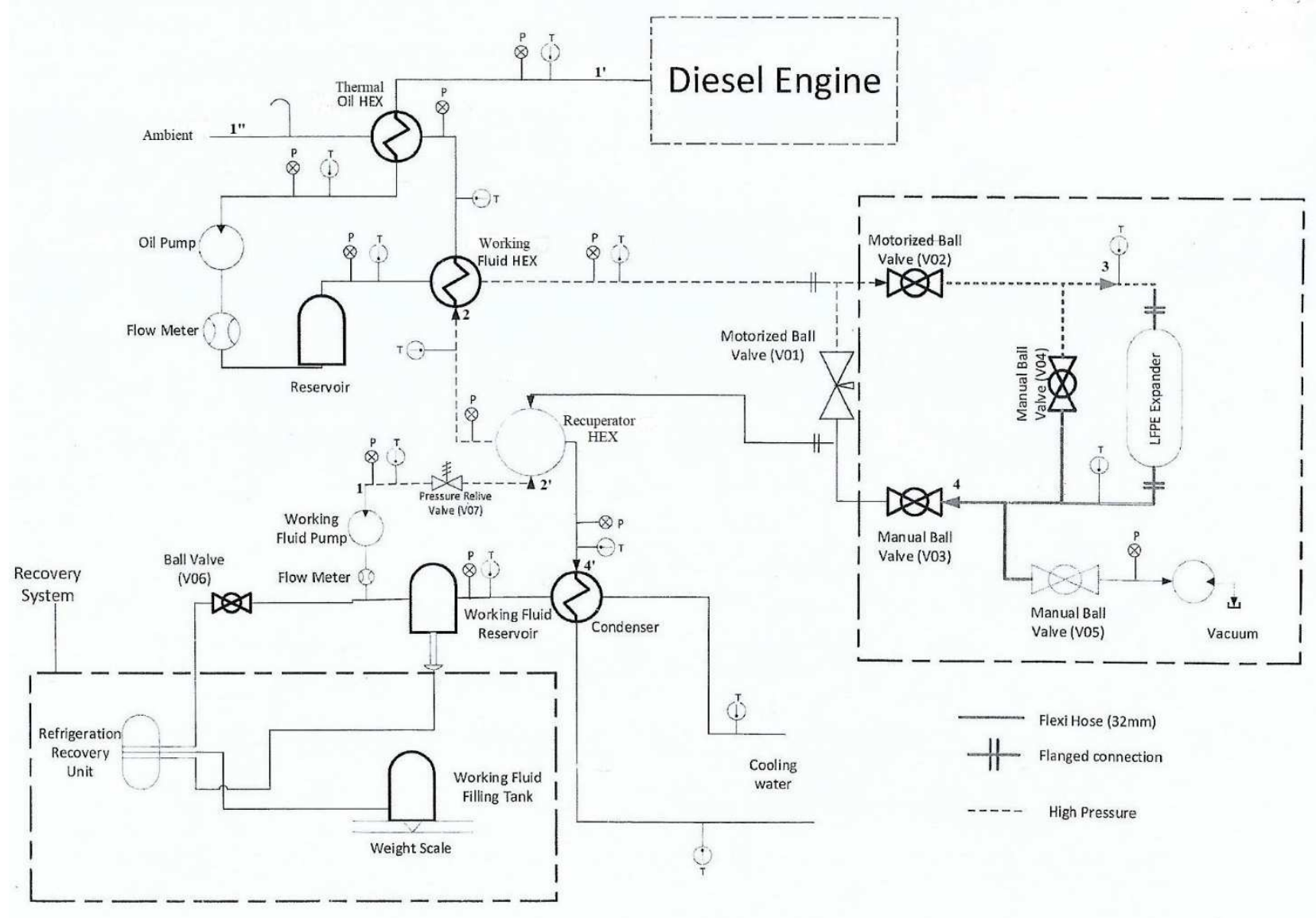

Figure 1. Test Bench Layout.

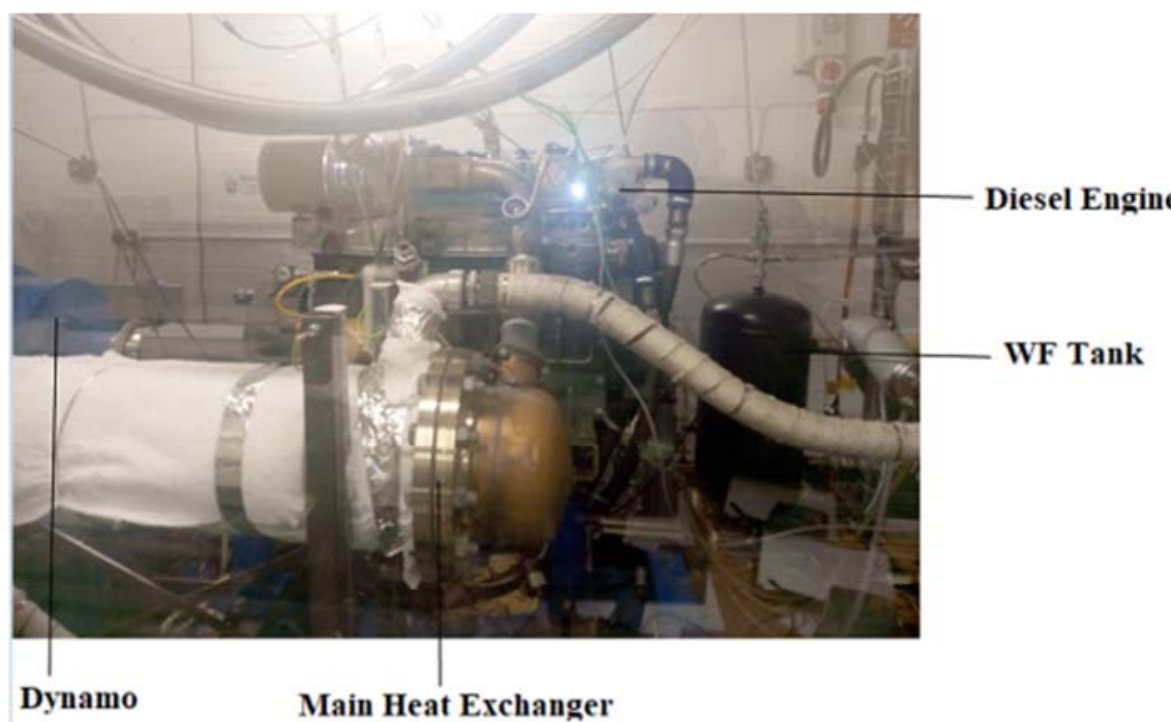

Figure 2. Primary Components of the Test-bench. 


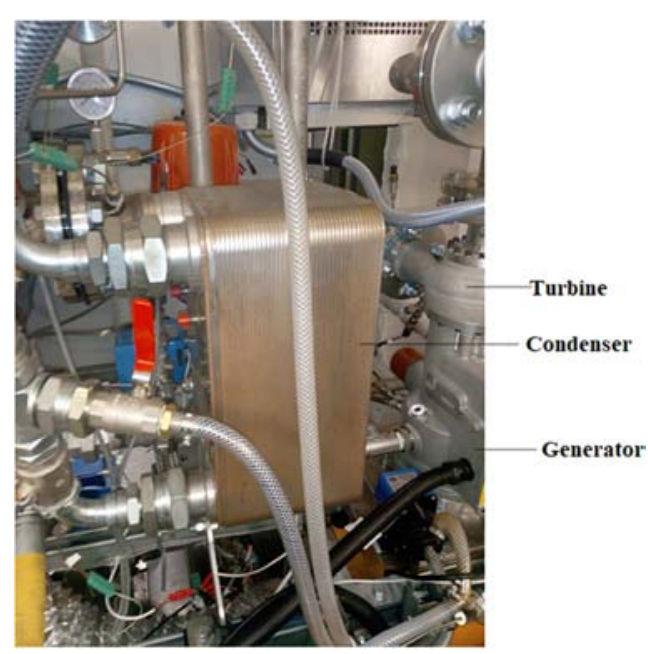

Figure 3. Other Constituents of the Experimental Set-up.

\section{Results and Discussions}

The experimental study was performed to investigate an ORC model's performance designed for exhaust heat recovery in truck engines and determine the potentials of adopting the technology on-board highway trucks. The system was allowed to attain steady-state conditions before recording results and then maintained at this state for about 1200 seconds. The experimental testing was performed at $40 \%$ part-load, in a view to achieve real-time operating condition vehicles hardly operate at full speed and load in real-world conditions in which the model will be subjected when installed.

Figure 4 shows the distribution of engine exhaust temperatures with time. The plot indicates that the exhaust temperature increases with time even though the system operates at a steady state, reflecting that it gets warmer with time. The engine exhaust temperature distribution falls within the range of 451 to $456^{\circ} \mathrm{C}$ at a steady state. Figure 5 depicts the evolution of working fluid and thermal oil mass flowrates with time. The graph shows working fluid mass flowrates range of 0.01 to $0.44 \mathrm{~kg} / \mathrm{s}$, while the thermal oil flow rate increases from 0.41 to $0.53 \mathrm{~kg} / \mathrm{s}$ with the system operating at a steady state. The results show that despite the operation at constant speed and load, the exhaust gas parameters and the ORC unit's performance increase as the system gets heat-up. The plot also shows that the working fluid flowrate has a steep increase at certain points (Around 250-300 secs) while the thermal oil flowrates demonstrate a slopy increase with time.

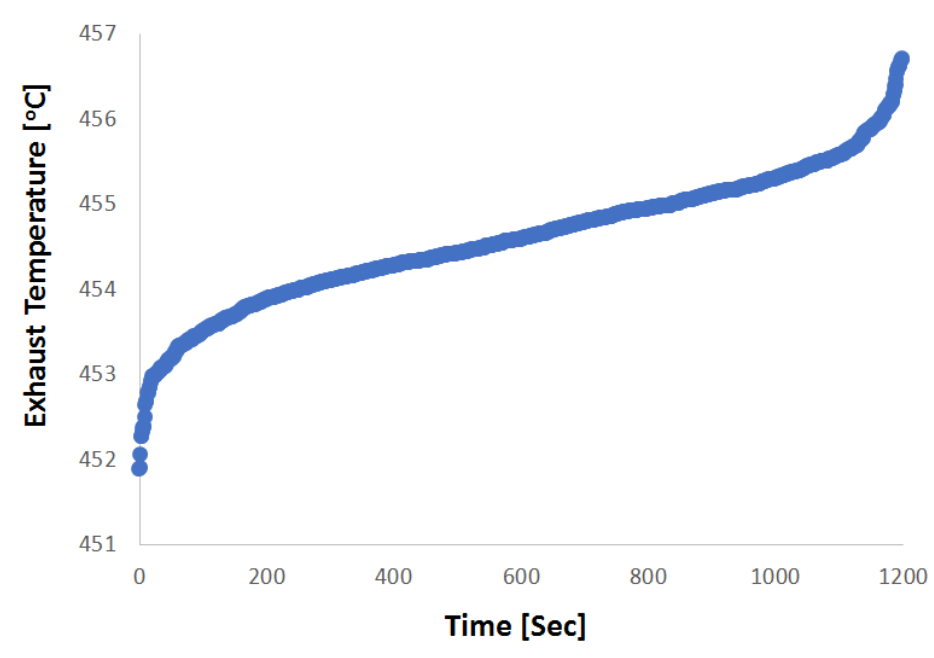

Figure 4. Engine Exhaust Temperature.

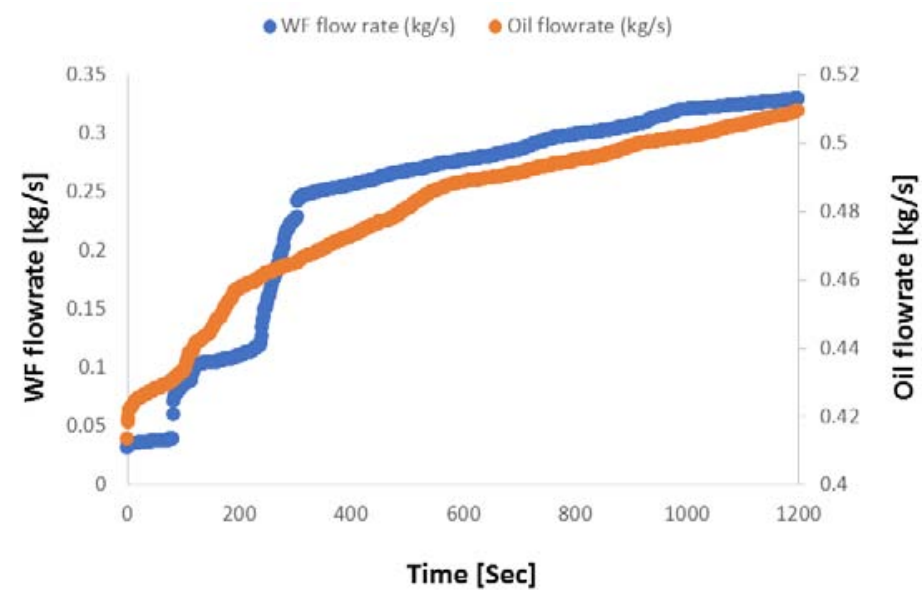

Figure 5. Evolution of Working Fluid and Thermal Oil Mass Flowrates. 


\section{Thermal Performance}

The study's objective function is to evaluate the ORC model's thermal performance coupled to the truck engine for exhaust energy recovery to assess the potentials of the system. The overall output and thermal efficiency measure the model's performance and net power output of the ORC module recovered from the combustion exhaust. Figure 6 presents the overall electric power output and the pump consumption recorded during the testing period. The output power has values ranging from 0.2 to $4.2 \mathrm{~kW}$ with a slight drop at around 450 to 500 seconds of recording time. This slight drop is due to the dynamo operation's fluctuation because it operates at around $40 \%(80 \mathrm{~kW})$ of the rated engine power. Meanwhile, the pump power consumption has a value ranging from 0.015 to $0.6 \mathrm{~kW}$ approximately, and the difference between the overall output power and pump consumption gives the net power output of the ORC model. The pump power consumption can be determined using the expression:

$$
\dot{W}_{\text {elec }}=\dot{m}_{w f}\left(h_{\text {out }}-h_{\text {in }}\right)
$$

Where $h_{\text {in }}$ and $h_{\text {out }}$ are the enthalpies of the working fluid in and out of the working fluid pump

The expression for the calculating the turbine electric power is given as:

$$
\dot{W}_{\text {turb }}=\dot{m}_{w f}\left(h_{\text {in }}-h_{\text {out }}\right)
$$

Where $h_{\text {in }}$ and $h_{\text {out }}$ are the enthalpies of the working fluid vapour in and out of the expansion machine.

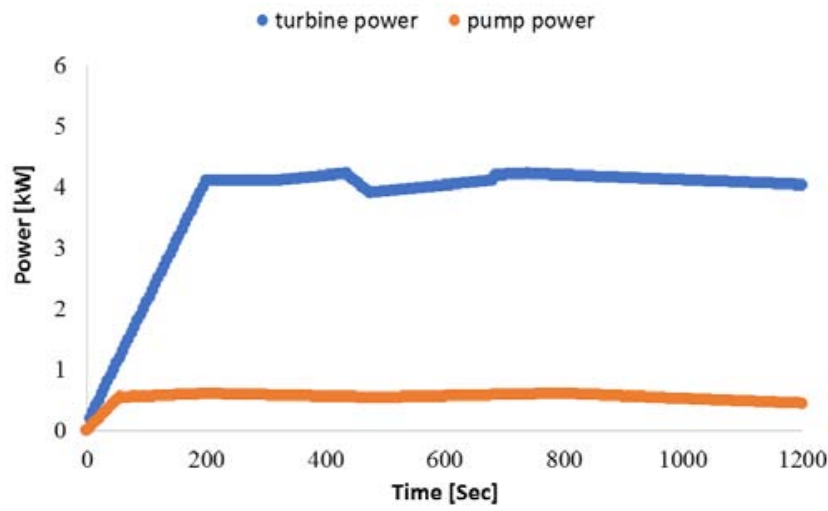

Figure 6. ORC System Power Output and Pump Consumption.

Figure 7 presents the net power output and the ORC model's cycle efficiency in this study. The graph shows the net power ranging from 0.15 to $3.6 \mathrm{~kW}$ during the operating time. The plot also presents the ORC system's cycle efficiency with values ranging from 0.1 to $5.2 \%$ as recorded during the testing period. The cycle efficiency of the system is determined using the expression:

$$
\eta_{t h}=\frac{\dot{W}_{\text {net }}}{\dot{Q}_{\text {in }}} \times 100
$$

Where $\dot{Q}_{\text {in }}$ is heat transferred to the working fluid.
The ORC net output is determine using the expression:

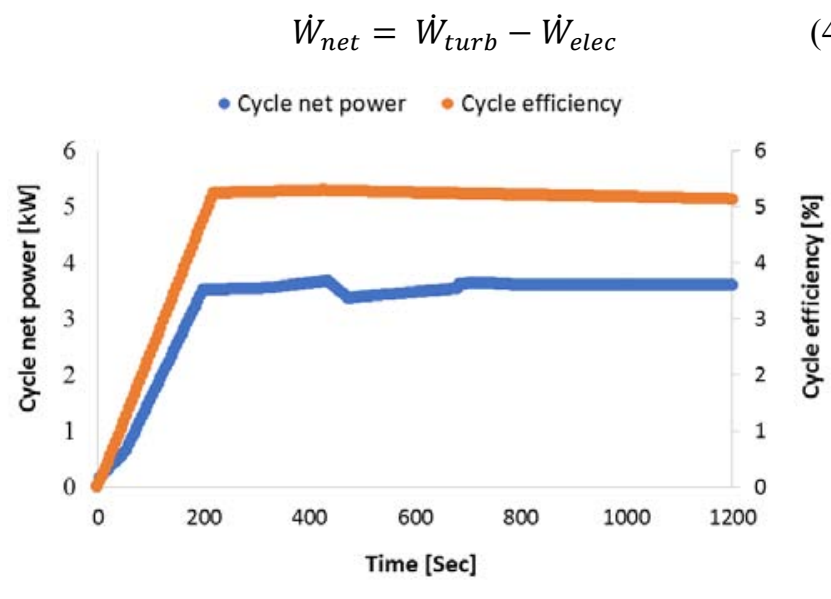

Figure 7. ORC Unit Net Output.

Figure 8 describes the relationship between the generated electric power and the working fluid's mass flow rate. The plot shows that the generated power increases with an increase in working fluid mass flow rate. This effect of increase generated power with increase mass flowrates demonstrates the contributing effect of the fluid flowrate in recovering the energy in the engine's exhaust; thus, fluid circulation is also an optimization parameter for consideration when improving the ORC's performance system.

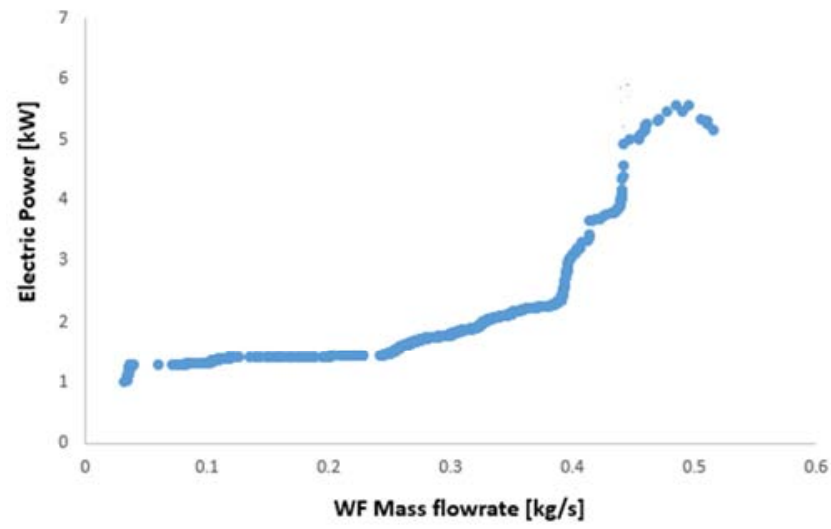

Figure 8. ORC System Thermal Efficiency.

\section{Conclusion}

This article presents the feasibility study of applying the ORC system for exhaust heat recovery in commercial truck engines. The test comprises an ORC system coupled to a Yuchai diesel engine to reuse the exhaust gas's thermal energy to improve its thermal performance without extra fuel consumption. The study with the objective function of evaluating the system thermal performance achieved maximum output electric power of $4.22 \mathrm{~kW}$, ORC net output of $3.67 \mathrm{~kW}$ maximum, and maximum cycle efficiency of $5.28 \%$. The test results performed the primary objective function, and the promising future of applying this 
technology in long-haul trucks for exhaust heat recovery was also examined.

\section{References}

[1] Thaddaeus, J., Pesiridis, A., \& Karvountzis-Kontakiotis, A. (2016). Design of variable geometry waste heat recovery turbine for high efficiency internal combustion engine. Int. J. Sci. Eng. Res, 7, 1001-1017.

[2] Pei, G., Li, J., Li, Y., Wang, D., \& Ji, J. (2011). Construction and dynamic test of a small-scale organic rankine cycle. Energy, 36 (5), 3215-3223.

[3] Julius Thaddaeus, Godwin Unachukwu, Chigbo Mgbemene, Ahmed Mohammed and Apostolos Pesyridis (2020): Overview of recent developments and the future of organic Rankine cycle applications for exhaust energy recovery in highway truck engines, International Journal of Green Energy, DOI: 10.1080/15435075.2020.1818247.

[4] Thaddaeus J, Unachukwu GO, Mgbemene CA, Pesyridis A, Alshammari FA (2020) Exergy and economic assessments of an organic rankine cycle module designed for heat recovery in commercial truck engines. Indian Journal of Science and Technology $13 \quad$ (37): 3871-3883. https://doi.org/10.17485/IJST/v13i37.1299.

[5] Wang, H., Peterson, R. B., and Herron, T. (2009). Experimental performance of a compliant scroll expander for an organic Rankine cycle. Proc. IMechE Vol. 223 Part A: J. Power and Energy 863-872. DOI: 10.1243/09576509JPE741.

[6] Qiu, G., Shao, Y., Li, J., Liu, H., and Riffat, S. B. (2012). Experimental investigation of a biomass-fired ORC-based micro-CHP for domestic applications. Fuel, 96, 374-382.

[7] Zheng, N., Zhao, L., Wang, X. D., and Tan, Y. T. (2013). Experimental verification of a rolling-piston expander that applied for low-temperature Organic Rankine Cycle. Applied Energy, 112, 1265-1274.

[8] Jung, H. C., Taylor, L., and Krumdieck, S. (2015). An experimental and modelling study of a $1 \mathrm{~kW}$ organic Rankine cycle unit with mixture working fluid. Energy, 81, 601-614.
[9] Galindo, J., Ruiz, S., Dolz, V., Royo-Pascual, L., Haller, R., Nicolas, B., and Glavatskaya, Y. (2015). Experimental and thermodynamic analysis of a bottoming Organic Rankine Cycle (ORC) of gasoline engine using swash-plate expander. Energy Conversion and Management, 103, 519-532.

[10] Surwase, P. B., \& Farkade, H. S. (2016). Waste Heat Recovery from the Exhaust of a Diesel Engine Using Parallel Flow Shell and Tube Heat Exchanger. Int. J. Mech. Prod. Eng, 4 (6), 2320-2092.

[11] Kolasiński, P., Błasiak, P., and Rak, J. (2016). Experimental and numerical analyses on the rotary vane expander operating conditions in a micro-organic Rankine cycle system. Energies, $9(8), 606$.

[12] Bianchi, M., Branchini, L., De Pascale, A., Orlandini, V., Ottaviano, S., Pinelli, M., and Suman, A. (2017). Experimental performance of a micro-ORC energy system for low grade heat recovery. Energy Procedia, 129, 899-906.

[13] Li, L., Ge, Y. T., and Tassou, S. A. (2017). Experimental study on a small-scale R245fa organic Rankine cycle system for low-grade thermal energy recovery. Energy Procedia, 105, $1827-1832$.

[14] Alshammari, F., Pesyridis, A., Karvountzis-Kontakiotis, A., Franchetti, B., and Pesmazoglou, Y. (2018). Experimental study of a small-scale organic Rankine cycle waste heat recovery system for a heavy-duty diesel engine with focus on the radial inflow turbine expander performance. Applied Energy, 215, 543-555.

[15] Fuhaid Alshammari, Apostolos Pesyridis (2019). Experimental study of organic Rankine cycle system and expander performance for heavy-duty diesel engine. Energy Conversion and Management, Volume 199, 111998, ISSN 0196-8904, https://doi.org/10.1016/j.enconman.2019.111998.

[16] Carstensen, A., Horn, A., Klammer, J., and Gockel, J. (2019). Waste Heat Recovery in Passenger Cars and Trucks. MTZ worldwide, 80 (4), 50-57.

[17] YuchaiYC6A280-30 Engine Specifications. Available from: $\mathrm{http} / / /$ en.yuchaidiesel.com/product/1680.html. 